\title{
Amateur Astronomy in France, 1789-1830: Two Examples
}

Simone Dumont ${ }^{1}$ and Solange Grillet ${ }^{2}$

${ }^{1}$ Laboratoire d'Astrophysique Théorique, IAP

98 bis Bd. Arago, F-75014 PARIS, France

${ }^{2}$ Observatoire de Paris, 61 av. de l'Observatoire, F-75014 Paris, France

\begin{abstract}
Historical events affected astronomy in France at this period. Large instruments were also rare so amateurs were on equal terms with professionals. Two significant amateurs are described:

Honore Flaugerges (1755-1830), justice of the peace at Viviers (Ardèche), observed from 1782 until his death, in particular discovering two comets and recording sunspots.

Anne-Jean P.C. Duc-Lachappelle (1765-1814), studied astronomy in Paris, and set up an observatory in Montauban in 1789, mainly observing planets and Mercury in particular. He had one pupil, Bernier, and set up a local society for arts and sciences in 1796.

Both of these astronomers had numerous contacts with professional astronomers throughout Europe.
\end{abstract}

